\title{
Translation of a standardized manufacturing protocol for mesenchymal stromal cells: A systematic comparison of validation and manufacturing data
}

\author{
MARKUS THOMAS ROJEWSKI ${ }^{2}$, RAMIN LOTFI $^{1,2}$, CECILIE GJERDE $^{3}$, \\ KAMAL MUSTAFA ${ }^{3}$, ELENA VERONESI ${ }^{4}$, AYMEN B. AHMED $^{5,6}$, MARKUS WIESNETH $^{2}$, \\ SIXTEN KÖRPER ${ }^{2}$, LUC SENSEBÉ ${ }^{7,8}$, PIERRE LAYROLLE $^{9}$, SØLVE HELLEM $^{3}$ \& \\ HUBERT SCHREZENMEIER ${ }^{1,2}$
}

\author{
${ }^{1}$ Institute for Transfusion Medicine, University Hospital Ulm, Ulm, Germany, ${ }^{2}$ Institute for Clinical Transfusion \\ Medicine and Immunogenetics Ulm, German Red Cross Blood Donation Service Baden-Württemberg - Hessia, Ulm, \\ Germany, ${ }^{3}$ Institute of Clinical Dentistry, University of Bergen, Bergen, Norway, ${ }^{4}$ Department of Medical and Surgical \\ Sciences for Children $\mathcal{E}$ Adults, University Hospital of Modena and Reggio Emilia, Modena, Italy, ${ }^{5}$ Section for \\ Haematology, Department of Clinical Science, University of Bergen, Bergen, Norway, ${ }^{6}$ Department of Medicine, \\ Haukeland University Hospital, Bergen, Norway, ${ }^{7}$ UMR5273 Centre national de la recherche scientifique (CNRS), \\ UPS, Établissement francais du sang (EFS)-INSERM U1031, STROMAlab, Toulouse, France, ${ }^{8}$ Etablissement \\ francais du sang (EFS) Pyrénées-Méditeranée, Toulouse, France, and ${ }^{9}$ Inserm U957, Laboratory for Pathophysiology of \\ Bone Resorption, Faculty of Medicine, University of Nantes, Nantes, France
}

\begin{abstract}
Background: Many data are available on expansion protocols for mesenchymal stromal cells (MSCs) for both experimental settings and manufacturing for clinical trials. However, there is a lack of information on translation of established protocols for Good Manufacturing Practice (GMP) from validation to manufacturing for clinical application. We present the validation and translation of a standardized pre-clinical protocol for isolation and expansion of MSCs for a clinical trial for reconstitution of alveolar bone. Methods: Key parameters of 22 large-scale expansions of MSCs from bone marrow (BM) for validation were compared with 11 expansions manufactured for the clinical trial "Jaw bone reconstruction using a combination of autologous mesenchymal stromal cells and biomaterial prior to dental implant placement (MAXILLO1)" aimed at reconstruction of alveolar bone. Results: Despite variations of the starting material, the robust protocol led to stable performance characteristics of expanded MSCs. Manufacturing of the autologous advanced therapy medicinal product MAXILLO-1-MSC was possible, requiring 21 days for each product. Transport of BM aspirates and MSCs within $24 \mathrm{~h}$ was guaranteed. MSCs fulfilled quality criteria requested by the national competent authority. In one case, the delivered MSCs developed a mosaic in chromosomal finding, showing no abnormality in differentiation capacity, growth behavior or surface marker expression during long-term culture. The proportion of cells with the mosaic decreased in long-term culture and cells stopped growth after 38.4 population doublings. Conclusions: Clinical use of freshly prepared MSCs, manufactured according to a standardized and validated proto$\mathrm{col}$, is feasible for bone regeneration, even if there was a long local distance between manufacturing center and clinical site. Several parameters, such as colony forming units fibroblasts (CFU-F), percentage of CD34+ cells, cell count of mononuclear cells (MNCs) and white blood cells (WBCs), of the BM may serve as a predictive tool for the yield of MSCs and may help to avoid unnecessary costs for MSC manufacturing due to insufficient cell expansion rates.
\end{abstract}

Key Words: advanced therapy medicinal products, cell production, Good Manufacturing Practice, karyotyping, mesenchymal stromal cells, quality control, translational medicine

Correspondence: Markus Thomas Rojewski, PhD, Institut für Transfusionsmedizin, Universitätsklinikum Ulm und Institut für Klinische Transfusionsmedizin und Immungenetik Ulm gemeinnützige GmbH, Deutsches Rotes Kreuz Blutspendedienst Baden-Württemberg, Hessia, Helmholtzstr. 10, 89081 Ulm, Germany. E-mail: markus.rojewski@uni-ulm.de 


\section{Background}

Mesenchymal stromal cells (MSCs) are well known for their immunomodulatory $[1,2]$ and regenerative potential and have shown their applicability as a promising therapy for tissue regeneration, e.g., liver repair [3], osteoarthritis [4] and bone regeneration [5]. With more than one million procedures each year in Europe [6], bone is the most transplanted tissue in humans after blood. Bone losses of traumatic (e.g., non-union fractures) or pathological origin (e.g., tumors or jawbone cysts) are generally filled with an autologous bone graft or autologous bone marrow. Autologous bone transplantation is the gold standard therapy for bone reconstitution in oral and maxofacial surgery [7]. For this treatment, a piece of autologous bone is removed, commonly from the crista iliaca, causing a second bone defect in the patient with possible side effects like pain or nerve damage at the site of bone harvesting [8]. In addition, autologous bone therapy may fail, due to preterm transplant resorption $[9,10]$. MSCs have been shown to be present in almost every tissue [11]. Due to their limited number in tissues, MSCs have to be isolated from the original tissue and expanded ex vivo in clean rooms (class A in B) [12-14].

Different protocols for Good Manufacturing Practice (GMP)-compliant isolation and expansion of MSCs have been described previously [15-21], but there is a lack of information on the suitability of pre-clinical protocols for experimental settings and animal models and their translation for GMP-compliant manufacturing of MSCs for clinical trials. We present the validation and translation of a standardized pre-clinical protocol [12] for isolation and expansion of MSCs for a clinical trial for reconstitution of alveolar bone (Jaw bone reconstitution using a combination of autologous mesenchymal stem cells and biomaterial prior to dental implant placement; MAXILLO-1 [EudraCT number 2012-00313930; ClinicalTrials.gov identifier NCT02751125]) as an example for translation of manufacturing protocols for clinical trials in other indications.

Expanded MSCs for clinical applications are classified as an advanced therapy medicinal product (ATMP) according to the European Medicines Agency (EMA) regulation number 1394/2007 of the European Commission (EC) [22].

In this study, we describe the translation of a previously established protocol for GMP-compliant largescale expansion of bone marrow (BM)-derived MSCs [12] to produce clinical doses of 50-100 million MSCs for jawbone reconstruction prior to dental implant surgery for 11 patients participating in the clinical trial MAXILLO-1. The MSCs expanded according to the GMP-compliant protocol used in this study have previously been tested for their osteogenic in vivo bone formation potential in pre-clinical models
$[23,24]$. In these models, MSCs were immobilized on a macro-microporous biodegradable, resorbable biphasic calcium phosphate.

Minimal criteria for MSCs as defined by the International Society for Cellular Therapy (ISCT) $[25,26]$ or modifications of these criteria $[12-14,27,28]$ are required to define identity and describe impurities of the ATMP. Release parameters for the ATMP may vary and include microbial, endotoxin and mycoplasma testing, tests for viability, clonogenicity, identity and purity and functional tests, depending on the type of clinical trial and the demands from national competent authorities.

For most clinical trials using MSCs, the manufacturing centers and clinical centers are two individual institutions at distinct locations. In this study, a bi-directional transportation lasting $18-24 \mathrm{~h}$ was necessary to transport $\mathrm{BM}$ aspirate from the clinical site to the manufacturing center and to transport the ATMP back to the clinical site. Part of this study was to analyze feasibility of interaction between a clinical partner and a manufacturing center over a long distance. Freezing ATMP has been shown to be quite inefficient because the recovery rate and clonogenicity [29] are reduced by cryopreservation and the clinical center additionally has to manipulate the MSCs, which may alter the intended clinical dose. It is also not clear if and how quickly MSCs recover their full therapeutic activity after thawing. In principle, cryopreservation of MSCs is possible with loss of viability and clonogenicity, depending on the freezing protocol [30]. Several publications showed maintenance of cell viability, surface marker expression, plasticity [31] and function of MSCs (e.g., in a retinal ischemia/perfusion model) [32]. Viability of (adiposederived) MSCs after cryopreservation in animal-free formulations may, however, be less than $72 \%$ and reduced by more than $20 \%$ [29] as compared with pre-freezing viability with a recovery of down to $62 \%$. The viability rate is similar to the one observed for pre-clinical studies at $8^{\circ} \mathrm{C} \pm 3^{\circ} \mathrm{C}$ for transportation of MSCs expanded according to the protocol used in this study $[12,24]$.

Effects of changes on gene expression profiles by freezing and thawing are still unclear [33]. The occurrence of cryopreservation-induced apoptosis [34] and of freeze/thaw and osmotic stress [35] can be avoided when using non-cryopreserved cells. As summarized by Galipeau [36], clinical trials with human MSCs almost always use cryopreserved cells, whereas in the pre-clinical animal models, live, $\log$ phase of growth MSCs are used almost universally. It was important for this study to use noncryopreserved MSCs showing the full potential of bone formation when stored and transported at $4{ }^{\circ} \mathrm{C}$ within $24 \mathrm{~h}$ including transportation. When using freshly produced, unfrozen MSCs for therapy, optimization of transportation conditions is crucial. 
Therefore, the clinical site often is close to the manufacturing site. In this study we also showed that there is no necessity of a local association of manufacturer and operator when MSCs are shipped at $4^{\circ} \mathrm{C}$ at conditions previously established in a preclinical setting keeping the bone formation potential of the shipped cells $[23,24]$.

\section{Methods \\ Ethical approval and participating manufacturing and clinical centers}

$\mathrm{BM}$ (validation runs) was collected from volunteer healthy donors after written informed consent was obtained according to the Declaration of Helsinki and approval by the Ethics Committee of Ulm University (ethical approval numbers $21 / 10$ and 24/11). The clinical trial MAXILLO-1 (Jaw bone reconstruction using a combination of autologous MSCs and biomaterial prior to dental implant placement) was approved by the Norwegian ethical committee (2013/1284/ REKvest) and by the Norwegian Medicines Agency (13/12062-15). The clinical trial followed the European guidelines for advanced therapeutic medicinal products. The EudraCT number of the trial was 2012003139-50 and the trial was incorporated in the database ClinicalTrials.gov with the identifier NCT 02751125. The Institute for Clinical Transfusion medicine and Immunogenetics Ulm (Ulm, Germany, authorization number DE_BW_01_MIA_2013_0040/ DE_BW:91_IKT Ulm) received BM aspirates from the Section for Haematology, Department of Clinical Science, University of Bergen at the Department of Medicine, Haukeland University Hospital, Bergen, Norway, and delivered the ATMP to the Institute of Clinical Dentistry, University of Bergen, Norway.

\section{Donor screening}

BM donors were screened as described in the biomedical research protocol for the prospective interventional phase 1 clinical trial MAXILLO-1. In summary, donors were between 18 and 80 years (both genders), with lateral (width $5 \mathrm{~mm}$ or less) or vertical bone loss (focusing lateral bone loss) of the mandible behind the canine tooth and endented (at least one missing tooth) for more than 6 months in the region requiring reconstitution, and in good general health presenting with normal blood cell counts and renal and hepatic function within normal limits.

\section{Isolation and shipping of $B M$}

Aspiration of $25 \mathrm{~mL}$ (target) $\mathrm{BM}$ was performed in an operating room from the iliac crest after local anesthesia.
By a cutaneous point of puncture, two to three points of puncture of the posterior iliac spine were made with a trocar. BM was harvested by fraction of 2-4 $\mathrm{mL}$ in $20-\mathrm{mL}$ syringes, prefilled with heparin (ratiopharm). The harvest, in its primary packaging, was laid out in an isothermal box labeled according to Directive 2004/23/EC [37] and 2006/17/EC [38]. The transport temperature was between $18^{\circ} \mathrm{C}$ and $24^{\circ} \mathrm{C}$, with temperature traceability. Delivery to the manufacturing centers was ensured within $24 \mathrm{~h}$ by accompanied transportation using a qualified transportation company.

\section{GMP-compliant isolation and expansion of MSCs}

Isolation and expansion of MSCs from the BM aspirates was performed as previously described as two-step protocol, option 1 (TSP1) by Fekete et al. [12]. The different steps of the manufacturing process, the corresponding test parameters and the responsibilities are summarized in Supplementary Table 1. Disposables, reagents and excipients are listed in Supplementary Table 2 and Supplementary Table 3. In brief, BM was directly seeded without any further manipulation in Minimal Essential Medium Eagle, alpha formulation (alpha-MEM medium) supplemented with 5\% platelet lysate (PL) and $1 \mathrm{IU}$ heparin/mL at a concentration of $50000 \mathrm{BM}$ white blood cells per $\mathrm{cm}^{2}$ in one to eight 2chamber CellStacks (Corning) at day 0 and incubated at $5 \% \mathrm{CO}_{2}$ atmosphere, $95 \%$ relative humidity at $37^{\circ} \mathrm{C}$. After 2-4 days, the supernatant was discarded and replaced by fresh alpha-MEM (Lonza) supplemented with 5\% PL (IKT Ulm) and $1 \mathrm{IU}$ heparin $/ \mathrm{mL}$. Twice a week, the supernatant was replaced by alpha-MEM supplemented with $5 \% \mathrm{PL}$ and $1 \mathrm{IU}$ heparin $/ \mathrm{mL}$. At day +14 , the cells were rinsed with Dulbeccos Phosphate Buffered Saline (DPBS, Lonza) and detached and MSCs of passage (P) 0 (MSCP0) were harvested using TrypZean (Lonza). Harvested cells were re-seeded at the concentration of $4 \times 10^{3} \mathrm{MSCP} 0$ per $\mathrm{cm}^{2}$ in alphaMEM medium supplemented with $8 \% \mathrm{PL}$ and $1 \mathrm{IU}$ heparin $/ \mathrm{mL}$ in one to seven 2-chamber CellStacks. Twice a week, the supernatant was replaced by alphaMEM supplemented with 8\% PL and 1 IU heparin/ $\mathrm{mL}$. At day 21, the cells were rinsed with DPBS and harvested using TrypZean. Cells were resuspended in a $5 \%$ albumin solution (CSL Behring) to obtain the final product MAXILLO-1 on which quality controls were applied. Cells were packaged and labeled for the shipment to the clinical center at the University of Bergen. All the materials and reagents used for the production were selected due to their suitability during the validation process to ascertain their compliance to be used in the manufacturing process. Specifications of the final product were as described in Supplementary Table 4. 


\section{Clonogenicity (colony forming units fibroblasts; CFU-F)}

BM aspirate was seeded in duplicates in T25 flasks (Nunc Thermo Scientific) at the same cell density as the main culture using the same culturing conditions. For MSC of passage 0 (MSCP0), MSC of passage 1 (MSCP1) duplicates of 200 and 400 cells per T25 flask were seeded at the same culturing conditions as the main culture. After 10 days, the medium was discarded and cells were Giemsa-stained (Sigma) on T25 flasks. Clonogenicity was assessed by counting colonies consisting of more than 50 cells/colony.

\section{Differentiation capacity}

Differentiation of MSCP1 was performed as described previously in detail $[12,13,39-41]$, using the commercially available kits for adipogenic (Lonza), chondrogenic (Miltenyi Biotech) and osteogenic (Miltenyi Biotech) differentiation.

\section{Quality controls: microbial testing, mycoplasma screening, endotoxin testing, karyotyping and flow cytometry}

Microbial testing was performed after matrix validation according to chapter 2.6.27 of the European Pharmacopoeia (Ph Eur) 8.0 [42] using the BacT/ALERT iAST aerobic and BacT/ALERT iNST anaerobic culture bottles (Supplementary Table 2) in a BacT/ ALERT 3D system (BioMerieux). Samples were shipped to an accredited contract laboratory, the Institute for Transfusion Medicine and Immunology, Mannheim, Germany, for mycoplasma testing using polymerase chain reaction (PCR) as previously described [43] after matrix validation according to chapter 2.6.7/2.6.21 of the Ph Eur 8.0 [42] and to Labor L+S AG, Bad Bocklet-Groenbrach, Germany for endotoxin testing by Limulus amebocyte lysate (LAL) test after matrix validation according to chapter 2.6.14 of the Ph Eur 8.0 [42].

For karyotyping, $100 \times 10^{3}-200 \times 10^{3}$ MSCP0 were seeded in $42 \mathrm{~mL}$ in a T175 flask (Nunc Thermo Scientific) for 2-4 days until the cells reached approximately $50 \%$ confluence. Colchizin $(1.63 \mathrm{~mL}$ of a $20 \mathrm{mg} / \mathrm{mL}$ solution from Eurobio) was added and incubated at $5 \% \mathrm{CO}_{2}$ atmosphere, $95 \%$ relative humidity at $37^{\circ} \mathrm{C}$ for at least $2 \mathrm{~h}$. Cells were rinsed once with $50 \mathrm{~mL}$ of DPBS, harvested by TrypZEAN treatment, collected in $10 \mathrm{~mL}$ of complete medium and transported within $2 \mathrm{~h}$ to the accredited contract laboratory, the Institute for Human Genetics, University Hospital Ulm (Ulm, Germany), for karyotyping according to the national guidelines [44,45] and the guidelines of the European Cytogeneticists Assocoation (E.C.A.) Permanent Working Group for Cytogenetics and Society $[46,47]$.
Flow cytometry was performed as previously described $[12,13,28]$. Approximately $1 \times 10^{6}-4 \times 10^{6}$ MSCPO or MSCP1 were stained per assay. In brief, cells were washed in DPBS and resuspended in $100 \mu \mathrm{L}$ of DPBS. Cells were stained with a combination of either immunoglobulin (Ig)G-fluorescein isothiocyanate (FITC) $(20 \mu \mathrm{L}$, clone X40), IgG-phycoerythrin (PE) $(20 \mu \mathrm{L}$, clone $\mathrm{X} 40)$ and IgG-peridinin chlorophyll protein (PerCP) $(20 \mu \mathrm{L}$, clone X40), or CD90FITC $(1 \mu \mathrm{L}$, clone 5E10), CD34-PE $(20 \mu \mathrm{L}$, clone $8 \mathrm{G} 12)$ and CD45-PerCP (20 $\mu \mathrm{L}$, clone $2 \mathrm{D} 1)$, or CD105-FITC (10 $\mu \mathrm{L}$, clone SN6), CD73-PE $(20 \mu \mathrm{L}$, clone $\mathrm{AD} 2)$ and $\mathrm{CD} 3-\mathrm{PE}(20 \mu \mathrm{L}$, clone SK7), or major histocompatibility complex class II (MHC cII) human leucocyte antigen (HLA)-DQ,DP-DR-FITC (20 $\mu \mathrm{L}$, clone Tü39) and major histocompatibility complex class I (MHC cI) HLA-A,B,C-PE $(20 \mu \mathrm{L}$, clone G46-2.6), respectively. Antibodies were purchased from BD Bioscience, except CD105 (Bio-Rad $\mathrm{AbD}$ Serotec $\mathrm{GmbH}$ ). After 15 to $20 \mathrm{~min}$ of staining at ambient temperature, cells were washed in DPBS and the fluorescence intensity of 50000 cells was acquired using a FACScan with CellQuest 3.3 software (BD Biosciences).

\section{Shipping of the ATMP}

The transportation of freshly detached MSCs at $5^{\circ} \mathrm{C} \pm 3^{\circ} \mathrm{C}$ was performed with temperature traceability. Delivery to the clinical center in Bergen was ensured within $24 \mathrm{~h}$ using a qualified transporter (World Courier [Deutschland] GmbH). Stability of the ATMP in 5\% saline solution has previously been demonstrated [24].

\section{Statistical analysis}

Statistical analysis was performed using GraphPad Prism 7.01 Software for Windows. D'Agostino \& Pearson normality test was performed for each dataset to test for normal distribution of data. In case of normal distribution, data were compared using the unpaired $t$ test with Welch's correction; for datasets not passing the D'Agostino \& Pearson normality test, data were compared using the Mann-Whitney $U$ test. KruskalWallis test was used for multiple-parameter analyses. Differences were considered as significant for $P<0.01$ because of multiple testing of the dataset. The correlation between multiple parameters was assessed, computing Spearman correlation ( $r$ values) for every pair of the following datasets: time between end of aspiration and end of seeding $(\mathrm{h})$, age $(\mathrm{y})$, aspiration volume $(\mathrm{mL})$, aspiration volume without heparin $(\mathrm{mL})$, white blood cell count ([WBC] $/ \mu \mathrm{L})$, mononuclear cell count $([\mathrm{MNC}] / \mu \mathrm{L}), \% \mathrm{MNC}$ of WBC, \% CD34+ in BM aspirate, harvest density of MSCP0 (cells $/ \mathrm{cm}^{2}$ ), harvest 
density of MSCP1 (cells $/ \mathrm{cm}^{2}$ ), doubling time of MSCP0 (h), doubling time of MSCP1 (h), population doublings in $\mathrm{PO}$, population doublings in $\mathrm{P} 1$, cumulative population doublings, CFU-F $/ 10^{6} \mathrm{BM}-\mathrm{WBC}, \mathrm{CFU}-\mathrm{F} /$ $10^{6} \mathrm{MSCP} 0, \mathrm{CFU}-\mathrm{F} / 10^{6} \mathrm{MSCP} 1, \mathrm{MSCP} 0$ harvested/ $\mu \mathrm{L} \mathrm{BM}$ aspirate seeded and MSCP1 harvested/ $\mu \mathrm{L}$ BM aspirate seeded. Correlations with $r \geq 0.5$ and $P<0.05$ were considered as significant.

\section{Results}

\section{Donor characteristics}

Overall, 13 aspirations were performed in the context of the clinical trial MAXILLO-1 and 21 aspirations of $\mathrm{BM}$ were performed for validation. Production of two of the 13 aspirates for clinical trial MAXILLO-1 was stopped at passage 0 for patients 1-05 and 1-10 because the overall harvest of $0.9 \times 10^{6}$ and $1.2 \times 10^{6}$ cells in passage 0 was not sufficient to start passage 1 . In accordance with this, no CFU-F/ $10^{6} \mathrm{BM}-\mathrm{WBCs}$ were detected (data not shown). One BM from the validation was split (identification [ID] 7585) and two $\mathrm{BM}$ aspirates from patients within MAXILLO-1 had to be discarded (ID 1-05 and 1-10) due to lack of CFU-F in the aspirate and growth of the culture during the passage 0 growth phase (data not shown). Information on shipping and donor characteristics are presented in Supplementary Table 5 and Supplementary Figure 1 and summarized in Table 1.

The group of volunteer healthy donors and MAXILLO-1 patients differed significantly in age $(P<0.0001)$. Significant differences were also observed for clonogenicity of the BM aspirate (CFUF $/ 10^{6}$ BM-WBC; $P=0.0060$ ), time between end of aspiration and beginning of seeding, $\mathrm{WBC} / \mathrm{mL} \mathrm{BM}$ aspirate $(P<0.0001)$ and $\mathrm{MNC} / \mathrm{mL} \mathrm{BM}$ aspirate $(P<0.0001)$, whereas aspiration volume
$(P=0.2414)$ and the percentage of CD34 cells in the aspirate $(P=0.0946)$ did not significantly differ.

\section{MSC isolation and expansion for validation}

Detailed information on data for the expansions performed is shown in Table 2, Figure 1, Supplementary Table 6 and Supplementary Table 7.

\section{Validation}

For validation, BM-WBCs were seeded on $4307 \pm$ $2911 \mathrm{~cm}^{2}$ culture surface at a cell density of 49961 $\pm 264 \mathrm{cells} / \mathrm{cm}^{2}$. The first culture step was $13.8 \pm$ 0.1 days and resulted in a density of passage 0 MSC (MSCP0) of $25.7 \times 10^{3} / \mathrm{cm}^{2} \pm 15.7 \times 10^{3} / \mathrm{cm}^{2}$. This corresponds with $13.1 \pm 0.8$ population doublings with a doubling time of $25.4 \pm 1.6 \mathrm{~h}$. In the second culture step, $4008 \pm 2 \mathrm{MSCPO} / \mathrm{cm}^{2}$ were seeded on $5753 \pm 3481 \mathrm{~cm}^{2}$ and cultured for an additional 6.9 \pm 0.2 days. This culture resulted in a cell density of passage 1 MSC (MSCP1) of $49.1 \times 10^{3} / \mathrm{cm}^{2} \pm$ $18.0 \times 10^{3} / \mathrm{cm}^{2}$. This corresponds with $3.5 \pm 0.7$ population doublings with a doubling time of $51.7 \pm$ $24.1 \mathrm{~h}$. The cumulative number of population doublings was $16.6 \pm 1$.

The overall harvest of the final product was $283.2 \times 10^{6} \pm 187.3 \times 10^{6}$. The calculated yield was $17.5 \times 10^{3} \pm 14.8 \times 10^{3} \mathrm{MSCP} / \mu \mathrm{L} \mathrm{BM}$ aspirate and $230.6 \times 10^{3} \pm 245.3 \times 10^{3} \mathrm{MSCP} 1 / \mu \mathrm{L} \mathrm{BM}$ aspirate. This theoretically would have allowed a total harvest of $4540.2 \times 10^{6} \pm 5227.9 \times 10^{9}$ MSCP1 from as little as $23.6 \pm 8.2 \mathrm{~mL}$ of BM aspirate within $20.8 \pm 0.3$ days, based on the assumption that all $\mathrm{BM}$-WBCs of the $\mathrm{BM}$ aspirate were seeded in passage 0 and the total harvest of passage 0 was reseeded for passage 1 .

Table 1. Information on $\mathrm{BM}$ aspirates from validation runs (A) and manufacturing for the clinical trial MAXILLO-1 (B): age, volume of $\mathrm{BM}$ aspirate, WBC count/mL BM aspirate and number of CFU-F of BM aspirate per million BM WBCs.

\section{(A) Validation runs}

\begin{tabular}{lcccc}
\hline $\mathrm{N}=22$ & Donor age & Volume of aspirate $(\mathrm{mL})$ & Cell count WBC $\times 10^{6} / \mathrm{mL}$ BM aspirate & CFU-F of BM $/ 10^{6}$ WBCs \\
\hline Mean & 26 & 23.6 & 30.7 & 236 \\
SD & 7 & 8.2 & 15.7 & 160 \\
Minimum & 21 & 9.3 & 9.4 & 9 \\
Maximum & 49 & 42.5 & 62.4 & 453
\end{tabular}

(B) MAXILLO-1 patients

\begin{tabular}{lcccc}
\hline $\mathrm{N}=11$ & Patient age & Volume of aspirate $(\mathrm{mL})$ & Cell count WBC $\times 10^{6} / \mathrm{mL}$ BM aspirate & CFU-F of BM $/ 10^{6}$ WBCs \\
\hline Mean & 63 & 21.4 & 16.9 & 31 \\
SD & 6 & 2.0 & 8.5 & 22 \\
Minimum & 51 & 19.0 & 6.5 & 2 \\
Maximum & 72 & 26.0 & 37.2 & 73 \\
\hline
\end{tabular}

$\mathrm{SD}$, standard deviation. 
Table 2. Key information of expansion process for MSCs from validation runs (A) and manufacturing for the clinical trial MAXILLO-1 (B): doubling time in passage 0 , passage 1 and number of population doublings in passage 0 and passage 1 and number of cumulative population doublings in passage 0 and passage 1 , achieved overall harvest of the final product (MSC of passage 1 ), and calculated yield (MSC/ $\mu \mathrm{L}$ BM aspirate) of MSCs for passage 0 and passage 1 .

(A) MSCs from validation runs

\begin{tabular}{|c|c|c|c|c|c|c|c|c|c|}
\hline & \multicolumn{2}{|c|}{ Doubling time } & \multicolumn{3}{|c|}{$\begin{array}{c}\text { Number of } \\
\text { population doublings }\end{array}$} & \multirow[t]{2}{*}{$\begin{array}{l}\text { Overall harvest } \\
\quad\left(\text { cells } \times 10^{6}\right)\end{array}$} & \multicolumn{2}{|c|}{$\begin{array}{c}\text { Calculated yield } \\
\left(\mathrm{MSC} \times 10^{3} / \mu \mathrm{L} \mathrm{BM}\right. \\
\text { aspirate) for } \\
\end{array}$} & \multirow[t]{2}{*}{$\begin{array}{l}\text { Hypothetical maximum } \\
\text { harvest }\left(\text { cells x } 10^{6} \text { ) }\right.\end{array}$} \\
\hline & $\mathrm{P} 0(\mathrm{~h})$ & P1 (h) & P0 & P1 & Cumulative (P0 and $\mathrm{P} 1)$ & & P0 & $\mathrm{P} 1$ & \\
\hline Mean & 25.4 & 51.7 & 13.1 & 3.5 & 16.6 & 283.2 & 17.5 & 230.6 & 4540.2 \\
\hline $\mathrm{SD}$ & 1.6 & 24.1 & 0.8 & 0.7 & 1.1 & 187.3 & 14.8 & 246.3 & 5227.9 \\
\hline Minimum & 21.8 & 38.7 & 11.7 & 1.2 & 14.4 & 11.9 & 0.5 & 6.6 & 13.6 \\
\hline Maximum & 28.4 & 155.4 & 15.2 & 4.3 & 19.1 & 740.8 & 54.6 & 1012.1 & 20141.3 \\
\hline
\end{tabular}

(B) MAXILLO-1 MSCs

\begin{tabular}{|c|c|c|c|c|c|c|c|c|c|}
\hline Mean & 25.3 & 49.3 & 13.4 & 3.4 & 16.8 & 273.7 & 5.3 & 63.2 & 1424.9 \\
\hline SD & 2.5 & 4.4 & 1.4 & 0.3 & 1.5 & 104.5 & 5.0 & 69.1 & 1653.5 \\
\hline Minimum & 20.5 & 44.1 & 11.1 & 2.9 & 14.5 & 53.3 & 0.5 & 5.3 & 103.8 \\
\hline Maximum & 30.3 & 57.1 & 16.4 & 3.8 & 20.2 & 412.0 & 18.3 & 243.5 & 5905.4 \\
\hline
\end{tabular}

The hypothetical maximum harvest indicates the maximum harvest that could have been achieved in case all aspirated BM was used for the MSC isolation and expansion process.

$\mathrm{P} 0$, passage $0 ; \mathrm{P} 1$, passage 1 .

\section{MAXILLO-1 patients}

From the MAXILLO-1 patients' BM aspirates, BM WBCs were seeded on $5493 \pm 2743 \mathrm{~cm}^{2}$ culture surface at a density of $49955 \pm 65 \mathrm{cells} / \mathrm{cm}^{2}$. The first culture step was $14.0 \pm 0.0$ days and resulted in a density of passage 0 MSC (MSCP0) of $13.4 \times 10^{3} / \mathrm{cm}^{2} \pm$ $7.0 \times 10^{3} / \mathrm{cm}^{2}$. This corresponds with $13.4 \pm 1.4 \mathrm{popu}-$ lation doublings with a doubling time of $25.3 \pm 2.5 \mathrm{~h}$. In the second culture step, $3882 \pm 374 \mathrm{MSCP0} / \mathrm{cm}^{2}$ were seeded on $6467 \pm 2132 \mathrm{~cm}^{2}$ and cultured for an additional $7.0 \pm 0.0$ days. This culture resulted in a density of passage 1 MSC (MSCP1) of $42.7 \times 10^{3} / \mathrm{cm}^{2}$ $\pm 9.4 \times 10^{3} / \mathrm{cm}^{2}$. This corresponds with $3.4 \pm 0.3$ population doublings with a doubling time of $49.3 \pm 4.4 \mathrm{~h}$. The cumulative number of population doublings was $16.8 \pm 1.5$.

The overall harvest of the final product was $273.7 \times 10^{6} \pm 104.5 \times 10^{6}$. Thus, the clinical dose of $2 \times\left[50 \times 10^{6}\right]$ MSCs could be produced in all cases except for patient 1-07. For this patient, a single dose of $50 \times 10^{6} \mathrm{MSC}$ was produced, fulfilling the specifications (Supplementary Table 4).

The calculated yield was $5.3 \times 10^{3} \pm 5.0 \times 10^{3}$ $\mathrm{MSCP} 0 / \mu \mathrm{L} \quad \mathrm{BM}$ aspirate and $63.2 \times 10^{3} \pm$ $69.1 \times 10^{3} \mathrm{MSCP} 1 / \mu \mathrm{L}$ BM aspirate. This theoretically would have allowed a total harvest of $1424.9 \times 10^{6} \pm 1653.5 \times 10^{6} \mathrm{MSCP} 1$ and production of a minimum of two to a maximum of 118 doses of $50 \times 10^{6} \mathrm{MSCP} 1$ from as little as $21.4 \pm$ $2.0 \mathrm{~mL}$ of $\mathrm{BM}$ aspirate within $21.0 \pm 0.0$ days when seeding all $\mathrm{BM}$ aspirate for passage 0 and all MSCP0 for generation of the ATMP.

\section{Statistical analysis}

When isolating and expanding MSCs, no significant differences of clinical relevant parameters between the group of volunteer healthy donors and MAXILLO-1 were observed for the parameters harvest density (MSCs $\left./ \mathrm{cm}^{2}\right)$ of MSCP1 $(P=0.19463)$, yield (MSCs harvested/ $\mu \mathrm{L} \mathrm{BM}$ aspirate seeded) of passage $0(P=0.0153)$ and passage $1(P=0.2134)$, population doublings in passage $0(P=0.5247)$, in passage $1(P=0.7485)$ and cumulative population doublings $(P=0.6553)$, doubling time during passage 0 $(P=0.3551)$ and passage $1(P=0.2484)$. There was a significant difference in harvest density (MSCs/ $\left.\mathrm{cm}^{2}\right)$ of MSCPO $(P=0.0048)$. This difference, which disappears during further passaging, is reflected by different CFU-F counts in the BM aspirates and may be caused by differences in the transportation time and age of donors in the group of volunteer healthy donors and MAXILLO-1 patients.

\section{Quality controls}

All quality controls were carried out according to the Ph Eur (Supplementary Table 8) for the corresponding method and all matrices have been validated for the tests applied.

\section{Viability}

Percentage of viable cells was $94.6 \% \pm 3.1 \%$ in the $\mathrm{BM}$ aspirate (BM-MNC), $97.0 \% \pm 3.2 \%$ for MSCP0 

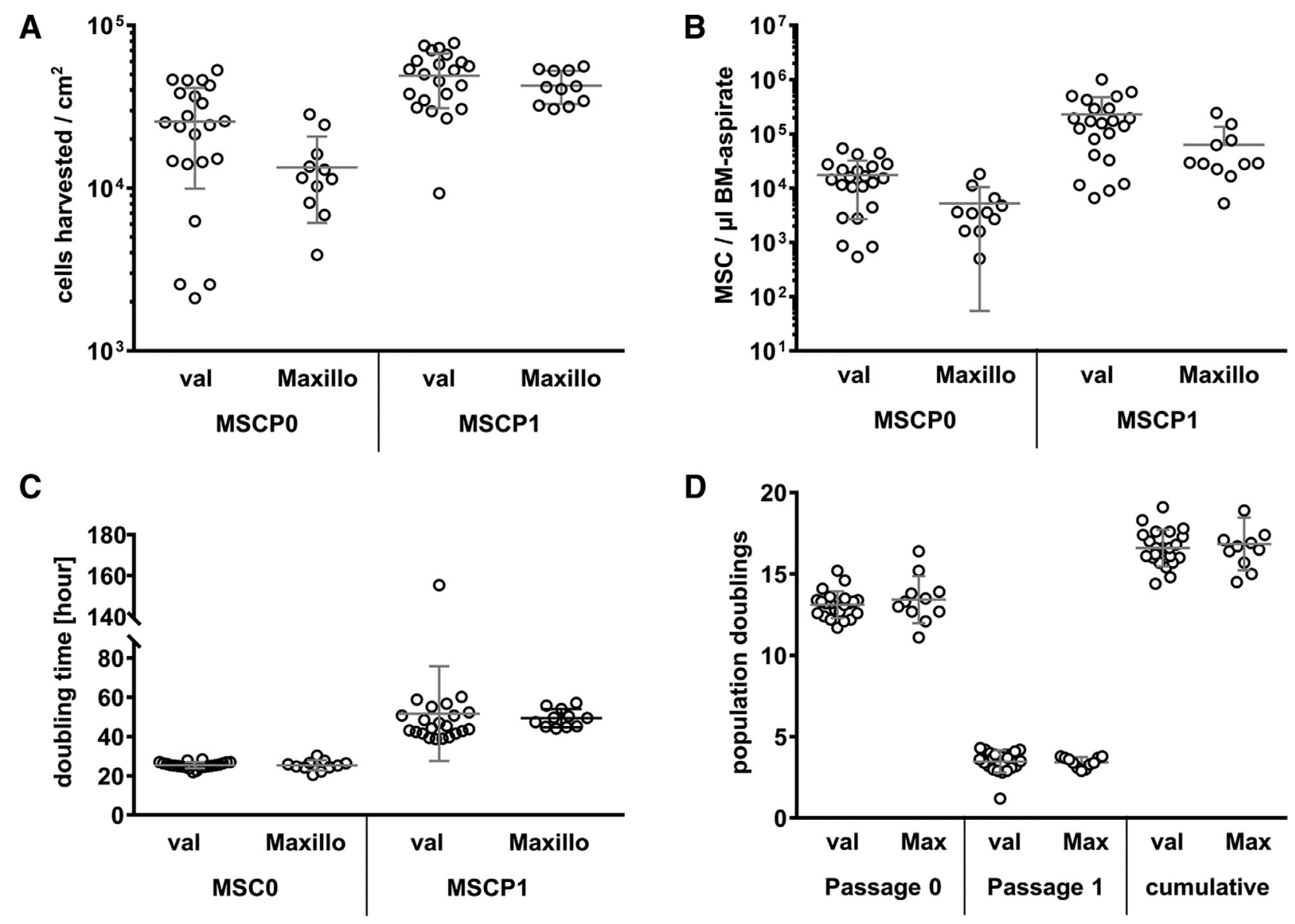

Figure 1. Key parameters of cell expansion. (A) MSC harvesting density (cells harvested $/ \mathrm{cm}^{2}$ ), (B) yield per $\mu \mathrm{L}$ BM aspirate seeded (MSCs/ $\mu \mathrm{L}$ BMaspirate) and (C) doubling times (doubling time $[\mathrm{h}]$ ), are shown for passage 0 and passage 1 for expansions used for the validation process and for the clinical trial MAXILLO-1. (D) Number of population doublings for MSCP0 and MSCP1 and the cumulative number of populations doublings is shown for expansions used for the validation process and for the clinical trial MacilloCT-1. Grey bars show mean and standard deviation. MSCP0, passage 0 MSC; MSCP1, passage $1 \mathrm{MSC}$; val, data for validation runs; Maxillo or Max, data for clinical trial MAXILLO-1.

and $94.5 \% \pm 4.2 \%$ for MSCP1 for validation runs (Table 3, Figure 2A and Supplementary Table 9).

For MAXILLO-1 patients, the percentage of viable cells was $92.5 \% \pm 3.5 \%$ in the starting material (BMMNC), $97.7 \% \pm 1.7 \%$ for harvested MSCP0 and $97.9 \% \pm 1.1 \%$, for the ATMP MAXILLO- 1 MSCs. No significant difference in viability of cells from $\mathrm{BM}$ $(P=0.0767)$, of MSCP0 cells BM $(P=0.8995)$ or MSCP1 BM $(P=0.0104)$ cells from volunteer healthy donors and MAXILLO-1 patients was seen. The Kruskal-Wallis test failed to reveal significant difference in viability of MSCP0 and MSCP1 between the two groups of donors.

\section{Impurities and identity}

The content of impurities of the starting material (i. e,. leukocytes or hematopoietic stem cells was determined by expression of CD3, CD34, CD45 and MHC cII on MSCP0; Table 4, Figure 2B and Supplementary Table 10) and MSCP1 (Table 4,
Figure $2 \mathrm{~B}$ and Supplementary Table 11) cells using flow cytometry. In summary, parameters for identity and impurity were fulfilled for all expansions from both volunteer healthy donors and MAXILLO-1 patients with one exception: MSCP1 expanded from volunteer healthy donor 7575 showed deviations for the parameters CD3 and CD105. The percentage of CD3+ cells was $23.5 \%$ (with an allowed threshold of $\leq 5 \%$ ), and the expression of CD105+ cells was $88.97 \%$ (with an allowed threshold of $\geq 90 \%$ ). Thus, only one preparation of 33 (i.e., $3 \%$ ) did not fulfill the release quality control criteria for identity and impurity.

\section{Clonogenicity (CFU-F)}

Expanded MSCs showed a clonogenicity of $192 \times 10^{3} \pm 72 \times 10^{3}$ colonies $/ 10^{6}$ seeded MSCP0 and of $210 \times 10^{3} \pm 79 \times 10^{3}$ colonies $/ 10^{6}$ seeded MSCP1 for cells from volunteer healthy donors and of $171 \times 10^{3} \pm 86 \times 10^{3}$ colonies $/ 10^{6}$ seeded 
Table 3. Percentage of viable cells in the starting material, for harvested passage $0 \mathrm{MSCs}(\%$ viable cells after harvest of $\mathrm{P} 0$ ) harvested passage 1 MSCs (\% viable cells after harvest of $\mathrm{P} 1$ ) from validation runs (A) and manufacturing for the clinical trial MAXILLO-1 (B).

\begin{tabular}{lccc}
\hline (A) MSCs from validation runs & & \\
\hline $\begin{array}{l}\text { \% of viable } \\
\text { cells }\end{array}$ & $\begin{array}{c}\text { In BM } \\
\text { aspirate }\end{array}$ & $\begin{array}{c}\text { After harvest } \\
\text { of P0 }\end{array}$ & $\begin{array}{c}\text { After harvest } \\
\text { of P1 }\end{array}$ \\
\hline Mean & 94.6 & 97.0 & 94.5 \\
SD & 3.1 & 3.2 & 4.2 \\
Minimum & 87.0 & 86.2 & 84.7 \\
Maximum & 98.2 & 100.0 & 99.6 \\
$\begin{array}{l}\text { Threshold for } \\
\text { release }\end{array}$ & ND & $\geq 80$ & $\geq 80$
\end{tabular}

(B) MAXILLO-1 MSCs

\begin{tabular}{lrrr}
\hline Mean & 92.5 & 97.7 & 97.9 \\
SD & 3.5 & 1.7 & 1.1 \\
Minimum & 86.9 & 94.4 & 93.3 \\
Maximum & 97.7 & 99.8 & 99.4 \\
$\begin{array}{l}\text { Threshold for } \\
\text { release }\end{array}$ & ND & $\geq 80$ & $\geq 80$ \\
\hline
\end{tabular}

Thresholds for release of the ATMP MAXILLO-1 are indicated at the bottom of the table.

$\mathrm{ND}$, not defined (declaration parameter only).

MSCP0 and of $91 \times 10^{3} \pm 40 \times 10^{3}$ colonies $/ 10^{6}$ seeded MSCP1 for cells from MAXILLO-1 patients. BM aspirates from volunteer healthy donors differed significantly in their CFU-F content $(P=0.0060)$ and MSCP1 showed significant difference in clonogenicity $(P=0.0003$; Figure 2C). Interestingly, MSCP0 from volunteer healthy donors and MAXILLO-1 patients did not differ in their clonogenic potential $(P=0.3551)$.

\section{Differentiation capacity}

Adipogenic, chondrogenic and osteogenic differentiation capacity was shown for all expansions performed for validation runs and in the context of MAXILLO-1. Representative photographs are shown in Supplementary Figure 2. All batches of MSCs exhibited a multipotent capacity in the three lineages.

\section{Microbial, endotoxin and mycoplasma testing}

Microbial testing of the starting material (BM), of the cell culture supernatant at day 7, of MSCP0 and of MSCP1 was negative for all expansions (Supplementary Table 12). Endotoxin testing was performed for all expansion and mycoplasma testing was performed for expansions in the context of the clinical trial MAXILLO- 1 and for 8 of the 22 cell expansions from volunteer healthy donors. For all tested products samples, anaerobic and aerobic cultures showed a negative test result. No mycoplasma DNA was detectable and endotoxin levels were $\leq 1 \mathrm{IU} / \mathrm{mL}$ in all cases.

\section{Karyotyping}

Karyotyping was set up for all 33 expansions. In one case (ID 1-07), only an insufficient number of metaphases could be achieved (Supplementary Table 13). A chromosomal change in only one metaphase could be detected for validation run ID 7537, 7543, 7562 and 7574 . From the occurrence of such abnormalities no conclusion can be made on the culture.

In one case (ID 1-04), four different chromosomal changes of the active substance were observed after release of the ATMP. The karyotype was as follows: 46,XX[29]; 46,XX,t(3;5;13)(p1?3;q33;p1)[6]; $46, X, ? \operatorname{inv}(X)$ (p22q1? [3]; and 46,X,+8[1]; 47,XX, +21 [1]. Two of the four changes occurred in more than one metaphase. To exclude chromosomal instability, immortalization and any effect on growth regulation, long-term cultures were set up.

\section{Long-term culture of MSCs from patient 1-04}

Cells were cultured in accordance with the expansion protocol for 5-19 days and passaged as indicated in Supplementary Table 14A. This process was continued until cells stopped growth. At each passage, the number of population doublings, doubling time and viability were determined. Karyotping of cells from passage 1, 2, 4, 7 and 9 was performed. In addition, identity of the cells by flow cytometry (Supplementary Table 14B) and adipogenic, chondrogenic and osteogenic differentiation capacity (Supplementary Figure 3) was assessed for cells of passage 4 and 7.

During long-term culture, cells with the chromosomal finding 46,X,?inv $(\mathrm{X})$ (p22q1?1[3], 46,X,+8[1] and $47, \mathrm{XX},+21[1]$ disappeared after one additional passage, whereas cells with the karyotype $46, \mathrm{XX}, \mathrm{t}$ $(3 ; 5 ; 13)(\mathrm{p} 1$ ?3;q33;p1) persisted until passage 7 (i.e., 34.9 cumulative population doublings of the CFU-F from $\mathrm{BM}$ ) but the relative proportion of cells with this marker decreased from $15 \%$ (passage 1) to $3 \%$ (passage 7). Cells seeded after nine passages stopped growth. The culture was maintained for 98 days. During this time, 38.4 population doublings occurred and the doubling time increased from $26.4 \mathrm{~h}$ (passage 0 ) to $340.9 \mathrm{~h}$ (passage 9). Viability was always $>80 \%$ and flow cytometry analysis showed that $<5 \%$ of cells were positive for CD3, CD45, CD34 and MHC cI and $>90 \%$ of cells were positive for CD73, CD90 and CD105 (Supplementary Table 14B). All these were release criteria for clinically applicable MSCs in MAXILLO-1. Interestingly, expression of MHC cI decreased to $75.75 \%$ for passage 7 cells. Patient 1-04 was screened a second time about half a year later with patient ID 1-11 

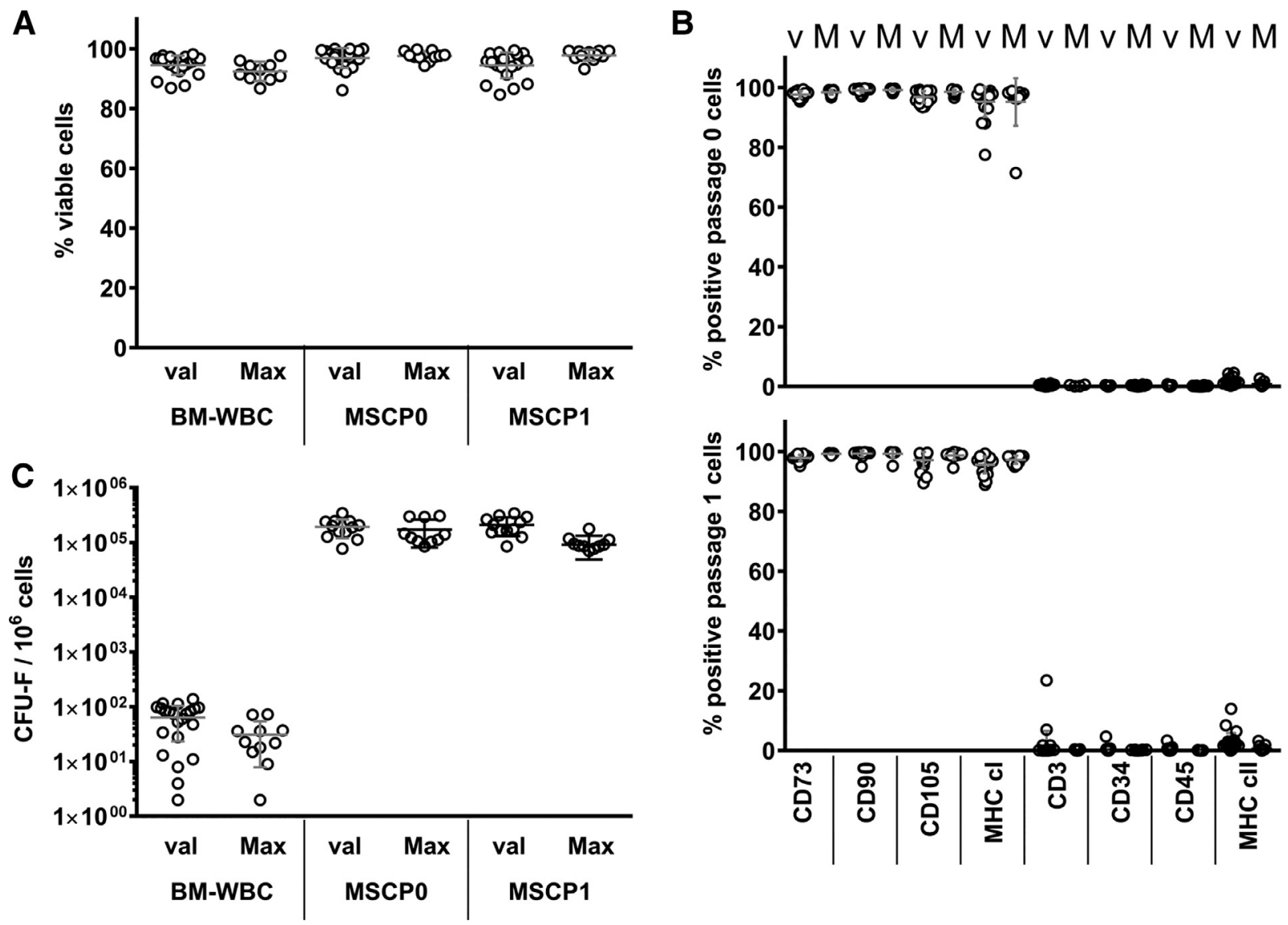

Figure 2. Key parameters of quality controls. (A) Percentage of viable WBCs in the BM aspirate and of viable MSCP0 and MSCP1, (B) results of flow cytometry analysis for identity (CD73, CD90, CD105 and MHC cI) and impurities (CD3, CD34, CD45 and MHC cII) of MSCP0 and MSCP1 and (C) number of colony-forming units fibroblasts per $10^{6}$ cells (CFU-F/ $10^{6}$ cells) for MNCs from BM aspirates, MSCP0 and MSCP1 are shown for expansions used for the validation process and for the clinical trial, respectively. Grey bars show mean and standard deviation.

[48] and cells were produced for transplantation of MSCs to the opposite mandibular site before dental implantation. For this second expansion, karyotyping was without findings. Overall, there was no evidence for expansion of the clone with the cytogenetic marker and no evidence for autonomous proliferation with appearance of phenotypically abnormal cells.

\section{Statistical correlations}

Statistical correlations were calculated based on all 33 expansions (both from volunteer healthy donors and MAXILLO-1 patients). Spearman correlation matrix for multiple-parameter analysis is shown in Supplementary Table S15A, and the corresponding $P$ value matrix is shown in Supplementary Table 15B.

As expected, a high correlation between BMWBC count and BM-MNC count $(r=0.8436 ; P<$ 0.0001 ) and between the percentage of CD34+ cells and BM-WBC $(r=0.5938 ; P=0.0005)$ count and BM-MNC count $(r=0.6351 ; P=0.0002)$ was observed because one of the inclusion criteria for treatment of MAXILLO-1 patients was the absence of hematopoietic disorders.

Effects of the parameters "age" and "transportation time" cannot be deciphered because transportation time for $\mathrm{BM}$ aspirates from elder donors (mainly MAXILLO-1 patients) was significantly higher (see donor characteristics) than transportation time for aspirates from younger patients (volunteer healthy donors). According to this, the correlation of age and transportation time was $r=0.7719(P<0.0001)$. Both age and transportation time show negative correlation with WBC count, MNC count, percentage of CD34+ cells in the BM aspirate, harvest density of MSCP0 (but not MSCP1), CFU-F from BM aspirate and MSCP1 (but not from MSCP0) and the yield of both MSCP0 and MSCP1 harvested per microliter BM aspirate seeded (for $r$ and $P$ values refer to Supplementary Table 15).

The percentage of CD34+ cells in BM aspirates correlated with the number of CFU-F from the BM aspirate $(r=0.6288 ; P<0.0002)$ and also with the harvesting density of MSCP0 $(r=0.6586 ; P=0.0001)$. In accordance with this, the number of CFU-F from the 
Table 4. Flow cytometry in process quality control of passage 0 MSC and control of validation runs (A) and the ATMP MAXILLO-1 MSC (B).

\begin{tabular}{|c|c|c|c|c|c|c|c|c|c|c|c|c|c|c|c|c|}
\hline & \multicolumn{8}{|c|}{$\%$ Positive MSCs of passage 0 for indicated marker } & \multicolumn{8}{|c|}{$\%$ Positive MSC of passage 1 for indicated marker } \\
\hline & $\mathrm{CD} 3$ & CD34 & $\mathrm{CD} 45$ & MHC cII & $\mathrm{CD} 73$ & CD90 & CD105 & MHC cI & $\mathrm{CD} 3$ & CD34 & $\mathrm{CD} 45$ & MHC cII & $\mathrm{CD} 73$ & CD90 & CD105 & MHC \\
\hline Mean & 0.07 & -0.12 & 0.08 & 1.47 & 97.71 & 99.09 & 96.93 & 95.32 & 1.43 & 0.12 & 0.23 & 2.67 & 97.91 & 99.39 & 97.21 & 95.65 \\
\hline SD & 0.44 & 0.38 & 0.28 & 1.21 & 1.18 & 0.73 & 1.95 & 4.88 & 5.07 & 1.11 & 0.77 & 3.14 & 1.07 & 0.98 & 2.67 & 2.78 \\
\hline Minimum & -0.60 & -1.34 & -0.41 & 0.30 & 95.41 & 97.20 & 93.56 & 77.58 & -0.90 & -1.38 & -0.76 & -0.06 & 95.29 & 95.08 & 89.54 & 88.97 \\
\hline \multirow[t]{3}{*}{ Maximum } & 1.06 & 0.53 & 0.80 & 4.60 & 99.49 & 99.80 & 99.36 & 99.45 & 23.51 & 4.74 & 3.39 & 14.02 & 99.43 & 99.89 & 99.72 & 99.41 \\
\hline & \multicolumn{8}{|c|}{ Thresholds for in process controls of passage 0 cells } & \multicolumn{8}{|c|}{ Thresholds for controls of the ATMP MAXILLO-1 MSCs } \\
\hline & $\leq 20$ & $\leq 20$ & $\leq 20$ & ND & $\geq 80$ & $\geq 80$ & $\geq 80$ & ND & $\leq 5$ & $\leq 5$ & $\leq 5$ & ND & $\geq 90$ & $\geq 90$ & $\geq 90$ & ND \\
\hline
\end{tabular}

(B) MAXILLO-1 MSCs

\begin{tabular}{|c|c|c|c|c|c|c|c|c|c|c|c|c|c|c|c|c|}
\hline & \multicolumn{8}{|c|}{$\%$ Positive MSC of passage 0 for indicated marker } & \multicolumn{8}{|c|}{$\%$ Positive MSC of passage 1 for indicated marker } \\
\hline & CD3 & CD34 & $\mathrm{CD} 45$ & MHC cII & CD73 & CD90 & CD105 & MHC cI & $\mathrm{CD} 3$ & CD34 & $\mathrm{CD} 45$ & MHC cII & CD73 & CD90 & CD105 & MHC \\
\hline Mean & -0.05 & 0.31 & 0.18 & 0.78 & 98.49 & 99.30 & 98.63 & 95.25 & 0.00 & 0.11 & 0.01 & 0,58 & 99.34 & 99.36 & 98.79 & 97.34 \\
\hline $\mathrm{SD}$ & 0.42 & 0.23 & 0.16 & 0.82 & 0.72 & 0.52 & 0.79 & 8.60 & 0.23 & 0.13 & 0.18 & 1.07 & 0.10 & 0.07 & 0.37 & 1.26 \\
\hline Minimum & -0.74 & -0.14 & -0.01 & 0.19 & 96.85 & 98.23 & 96.67 & 71.53 & -0.39 & -0.09 & -0.25 & -3.03 & 98.79 & 95.31 & 94.66 & 95.07 \\
\hline \multirow[t]{3}{*}{ Maximum } & 0.64 & 0.71 & 0.52 & 2.68 & 99.25 & 99.69 & 99.47 & 99.02 & 0.44 & 0.29 & 0.18 & 3.27 & 99.56 & 99.87 & 99.98 & 98.72 \\
\hline & \multicolumn{8}{|c|}{ Thresholds for in process controls of passage 0 cells } & \multicolumn{8}{|c|}{ Thresholds for controls of the ATMP MAXILLO-1 MSCs } \\
\hline & $\leq 20$ & $\leq 20$ & $\leq 20$ & ND & $\geq 80$ & $\geq 80$ & $\geq 80$ & ND & $\leq 5$ & $\leq 5$ & $\leq 5$ & ND & $\geq 90$ & $\geq 90$ & $\geq 90$ & ND \\
\hline
\end{tabular}

Thresholds for release are indicated at the bottom of the table. Negative figures mean that the proportion of positive cells after staining with the respective specific antibody was lower than percentage of positive cells in the isotype control. 
$\mathrm{BM}$ aspirate correlated positively with the harvesting density of MSCP0 $(r=0.8016 ; P<0.0001)$.

A positive correlation between WBC count in the $\mathrm{BM}$ aspirates and MSCP0 cells $(r=0.8522 ; P<$ $0.0001)$ and MSCP1 cells $(r=0.7721 ; P<0.0001)$ harvested per microliter BM aspirate as well as between MNC count in the BM aspirates and MSCP0 cells $(r=0.7865 ; P<0.0001)$ and MSCP1 cells $(r=0.7064$; $P<0.0001)$ harvested per microliter BM aspirate and between the percentage of CD34+ cells in the BM aspirates and MSCP0 cells $(r=0.7195 ; P<0.0001)$ and MSCP1 cells $(r=0.6163 ; P<0.0001)$ harvested per microliter BM aspirate was observed. The harvesting density of MSCP0 correlated positively with the clonogenicity of MSCP1 $(r=0.5035 ; P=0.0143)$. For the passage 1 culture step, there was a positive correlation between harvesting density and number of population doublings $(r=0.9771 ; P<0.0001)$ and, in accordance with this, a negative correlation between harvesting density and doubling time $(r=-0.9721 ; P<0.0001)$. For further correlations refer to Supplementary Table 15.

\section{Discussion}

\section{Production of cells}

In this study, we have presented validation data of a GMP-compliant protocol for MSC isolation and expansion and have proven the feasibility of this protocol to manufacture MSCs for a clinical trial. Pre-clinical studies (e.g., in the context of bone formation $[15,49]$ or osteoarthritis [4]) using non-cryopreserved MSCs from $\mathrm{BM}$ or adipose tissue have been performed previously, but to our knowledge a systematic comparison of data on growth behavior, yield and quality controls relevant for release of the cell product (i.e., the manufactured ATMP) obtained in the validation process and in manufacturing of the clinical product has not been performed before.

In this study we also have shown that the production of clinical doses of MSCs for the clinical trial MAXILLO-1 was possible from a remote production site. Transport of BM aspirate from Bergen (Norway) to Ulm (Germany) was possible within $24 \mathrm{~h}$ by using a conventional courier service. The shelf life of $24 \mathrm{~h}$ for freshly produced, non-cryopreserved, clinicalgrade MSCs was sufficient for release of the product and transportation from the manufacturing site in Ulm, Germany to the clinical site in Bergen, Norway, where the product was implanted the day after. Before starting the production of 11 clinical doses for jaw augmentation, the production process was validated using 22 expansions from BM aspirates of 21 volunteer healthy donors. The availability of volunteer healthy BM donors is limited and, because the age of patients treated within MAXILLO-1 was not predictable prior to the recruitment of patients for the clinical trial, the group of volunteer healthy donors and MAXILLO-1 patients could not be matched for parameters like gender, age, body mass index or smoker status. Volunteer healthy donors had an average age of 26 years, and MAXILLO- 1 patients had an average age of 62 years. In addition, mean time between end of aspiration and beginning of seeding was $6.7 \mathrm{~h}$ for volunteer healthy donors and $22.3 \mathrm{~h}$ for MAXILLO-1 patients. The high correlation for the parameters "donor age" and "time between end of aspiration and beginning of seeding" is caused by the experimental setting of this study, because transportation time for BM aspirates from elder donors (mainly MAXILLO-1 patients) was significantly higher than transportation time for aspirates from younger patients (volunteer healthy donors). Therefore, it is not possible to decipher the reason for significant differences of the two groups in clonogenicity of the BM aspirate (CFU-F $/ 10^{6} \mathrm{BM}-\mathrm{WBC}$ ), in $\mathrm{WBC} / \mathrm{mL} \mathrm{BM}$ and in $\mathrm{MNC} / \mathrm{mL} \mathrm{BM}$. Interestingly, the percentage of CD34+ cells in the aspirates did not significantly differ. The percentage of CD34+ cells in BM aspirates correlated with the number of CFU-F from the BM aspirate. However, Kurt Yuksel et al. [50] showed no correlation between the clonogenic potential of stromal cells (CFU-F) and hematopoietic cells (colony foming units granulocyte-macrophage; CFU-GM) for patients with hematologic malignancies, patients with a diagnosis of $\mathrm{BM}$ failure and patients without hematologic disease. Both, CD34+ cells in BM aspirates as well as CFU-F from the BM aspirate correlated with the harvesting density of MSCP0. Obviously, a high percentage of CD34-positive cells and/or high CFU-F count and/or high cell count of MNCs and/or WBCs in the BM aspirate also positively correlate with the yield of not only MSCP0, but also MSCP1. Because BM cell count and also the percentage of CD34+ cells can easily be assessed at the day of BM harvest, it may be possible to predict whether a determined cell target of MSCP1 can be achieved from each individual aspirate. Analysis of a higher number than 33 large-scale expansions and analysis of an independent set of expansions is necessary to calculate the positive predictive value and the validity of the above-mentioned assumption. Starting from only $23 \mathrm{~mL}$ of $\mathrm{BM}$ aspirate, a total harvest of $13.6 \times 10^{6}-20141.3 \times 10^{6}$ to MSCP1 within 21 days would have been possible when using the whole BM aspirate for cell expansion. This range of the hypothetical overall yield shows the necessity to screen for early available, reliable prediction parameters for calculation of the expectable yield. In the setting of large-scale manufacturing for clinical use, an appropriate cell number for seeding passage 0 has to be used, sufficient to guarantee the target dose of the 
respective clinical protocol, but not causing an "overproduction," taking account of economic issues.

Because published expansion protocols show a high variability, we compared the doubling times in this study with the doubling times from publications using a similar expansion protocol [51,52]. We obtained mean doubling times of about $25 \mathrm{~h}$ for cells in passage 0 and of about 39 and $44 \mathrm{~h}$ for passage 1 (Table 2). These doubling times are comparable to the ones published by Schallmoser et al. [52] (doubling time: 25 to $34 \mathrm{~h}$, and calculated from available data: 10.5 population doublings in 11-15 days) and by Schallmoser et al. [51] (doubling time: 36 to $89 \mathrm{~h}$, and calculated from available data: $2.7-6.7$ population doublings in 10 days; doubling time: 36 for comparable seeding density to the protocol in this study).

It is also important to mention that the harvesting density of MSCP0 correlated positively with the clonogenicity of MSCP1, indicating that a higher harvesting density in passage 0 might have a beneficial effect on clonogenicity of cells applied to the patient. For longterm cultures for up to 39 population doublings, replicative aging, induction of alkaline phosphatase, bone sialoprotein, osteocalcin and collagen 1 have been described [53]. It has been shown that donor age and the number of cumulative population doublings impact the quality of MSCs in long-term cultures [54,55]. Beane et al. [54] showed lower cell yields and impaired adipogenesis with age in rabbits. Long-term cultured BM-derived MSCs exhibited slower population doublings, increased senescence and inferior chondrogenic differentiation potential. It has previously been shown that CFU-F content [29] and bone morphogenetic protein 7 (BMP7) [32] secretion increased after cryopreservation. Comparisons of the CFU-F content after different handling or harvest procedures of the tissue $[56,57]$, from different tissue sites [56] or from donors with different malignancies [50] have been published, but to our knowledge nothing is known so far about the impact of seeding density of MSCs on their clonogenicity or capacity to form CFU-F in the straight following passages. We did not observe any significant correlation of harvesting density for passage 0 and the clonogenicity of the harvested cells from this passage, whereas Bartmann et al. [51] used a similar xenogenicfree expansion system for MSCs and observed an inverse correlation of seeding density to MSC proliferation and CFU-F frequency of the same passage.

\section{Quality controls and release of cells}

All cell productions performed for the clinical trial MAXILLO-1 fulfilled the release criteria accepted by the Norwegian Medicines Agency (NoMA) for this ATMP (Supplementary Table 4). During the validation process, cell marker surface expression of MSCP1 expanded from volunteer healthy donor 7575 showed deviations for the parameters CD3 and CD105. Overall, only one single expansion of 33 (i.e., $3 \%$ ) failed to pass quality controls for identity and impurities.

\section{Bone augmentation capacity of manufactured cells}

MSCs isolated and expanded to the described protocol showed in vivo bone formation potential. Seven MSC preparations manufactured in the context of validation were successfully used in combination with a biphasic calcium phosphate biomaterial $(\mathrm{BCP}+)$ to induce ectopic bone formation and bone regeneration of induced critical size defects of the calvaria in immunocompromised mice [23]. Bone formation was observed and human cells were detected in the freshly formed bone. MSCs for the clinical trial MAXILLO-1 were implanted into patients with severely atrophied mandibular bone and successful augmentation of alveolar bone was observed in all study participants and shown by histology and X-ray microtomography ( $\mu \mathrm{CT})$ images [48].

\section{Karyotyping}

We observed chromosomal abnormalities in 5 expansions (Supplementary Table 13). These findings occurred in 4 of 22 (i.e., 18\%) and in 1 of 11 (i.e., 9\%) MSCP1 obtained from volunteer healthy donors and MAXILLO-1 patients, respectively. However, because only one metaphase was affected, this observation was considered as irrelevant; from the occurrence of such abnormalities no conclusion can be made $[44-47,58,59]$. Only in two cases (donor 7574 and patient 1-04), a specific finding occurred with higher frequency. Long-term cultures were set up for MSCP1 from patient 1-04 with a total culture time of 105 days to exclude chromosomal instability, immortalization and any effect on growth regulation. Cells with the specific chromosomal finding $46, \mathrm{XX}, \mathrm{t}$ $(3 ; 5 ; 13)(\mathrm{p} 1$ ?3; $\mathrm{q} 33 ; \mathrm{p} 1)$ persisted until the culture stopped growth. The percentage of affected cells decreased from $15 \%$ to $3 \%$. The release criteria for identity, impurity and viability were fulfilled and adipogenic, chondrogenic and osteogenic differentiation potential of cells were fulfilled also for cells harvested from long-term culture passage 4 and passage 7. During the long-term culture, doubling time constantly increased until cells showed progressive growth arrest after 38.4 population doublings.

The MSCP1 with a positive finding in karyotyping were applied to the patient because results from karyotyping were available only after implantation. Noteworthy, the same patient was screened and included a second time for MAXILLO-1. Different individual patient IDs (1-04 and 1-11) were given for the two independent treatments on the left and right 
mandibular side. MSCP1 cells obtained in the second production process showed a normal female karyotype. No phenotypical abnormalities or changes in differentiation capacity were seen at any time point analyzed, neither for ID 1-04 nor for ID 1-11. In long-term culture, cells rather underwent senescent. This is in line with the clinical observations on patients who received the MAXILLO-1 MSCs and had an uneventful clinical course up to now (last follow-up May 2017) [48]. Overall, laboratory analysis and clinical observations of patient 1-04 did not reveal evidence for unlimited proliferation of the clonal population with a cytogenetic marker.

The presence of cells with atypical findings in karyotyping has previously been described for MSCs in the context of clinical trials to prevent acute graft-versus-host disease or to treat irradiation-induced lesions [60]. In five of 20 (i.e., 25\%) cases, chromosomal abnormalities occurred and $7-75 \%$ of the cells were affected by aneuploidies, independent from the culture protocol. These frequencies are in accordance with our observations. In all cases with chromosomal changes reported by Tarte et al. [60], human telomerase reverse transcriptase (hTERT) activity was not detectable using quantitative PCR. A recent publication reports an increase of hTERT activity and a high spontaneous malignant transformation of BM-derived MSCs in long-term cultures [61]. Transformation of MSCs occurred in $45.8 \%$ of long-term cultures and MSCs showed loss of expression of typical MSC markers like CD73 and CD90, down-regulated expression of CD105 and limited differentiation potential. We did not observe these alterations in surface marker expression and differentiation capacity, even in the long-term cultures of MSCs from patient 1-04. This difference may also be caused by different culture conditions. Røsland et al. [61] cultured cells in medium supplemented with fetal calf serum. In our study, cells were grown in a xenogenic free system using human platelet lysate as a source for growth factors. This difference may contribute to suppression of transformation and favor senescence. Nevertheless, the significance of karyotyping as quality control parameter thus remains questionable. Quantitative analysis of hTERT may be the quality parameter of choice.

\section{Conclusions}

In this study, we have shown that there is no need of close proximity between manufacturing facility for MSCs and the clinical center where the cells are applied, even if cryopreservation has to be avoided and freshly produced cells have to be shipped on wet ice. We demonstrated that several parameters, like CFU-F, percentage of CD34+ cells, cell count of MNCs and WBCs of the BM, may serve as predictive tools for the yield of MSCs and thus may help to develop strategies to avoid unnecessary costs for production of MSCs due to insufficient cell expansion rates. Further investigations may be necessary to interpret the physiological and clinical impacts of the positive correlation between harvesting density of MSCs from early passages with low numbers of population doublings and the clonogenicity in the straight following passages.

\section{Acknowledgments}

We appreciate the excellent assistance of Gisela Baur, Thomas Becker, Sarah Chester, Dorothee Erz, Silva Hopfensitz and Christina Späth from the Institute for Transfusion Medicine, University Hospital Ulm and of the study coordinator Marianne Emblem Lehmann from Haukeland University Hospital, University of Bergen. We would like to thank Dr. Daniel Fürst from Institute for Transfusion Medicine, University Hospital Ulm and Institute for Clinical Transfusion Medicine and Immunogenetics Ulm, German Red Cross Blood Donation Service for statistical advice. This work was supported by the European Union's Seventh Framework Programme for research, technological development and demonstration (grant number HEALTH-2009-1.4.2-241879 (REBORNE)). The materials presented and views expressed here are the responsibility of the author(s) only. The European Union Commission takes no responsibility for any use made of the information set out.

Disclosure of interests: The authors declare that they have no competing interests.

\section{References}

[1] Le Blanc K, Rasmusson I, Sundberg B, Gotherstrom C, Hassan M, Uzunel M, et al. Treatment of severe acute graft-versushost disease with third party haploidentical mesenchymal stem cells. Lancet 2004;363(9419):1439-41.

[2] von Bonin M, Kiani A, Platzbecker U, Schetelig J, Holig K, Oelschlagel U, et al. Third-party mesenchymal stem cells as part of the management of graft-failure after haploidentical stem cell transplantation. Leuk Res 2009;33(12):e215-7.

[3] Lanthier N, Lin-Marq N, Rubbia-Brandt L, Clement S, Goossens N, Spahr L. Autologous bone marrow-derived cell transplantation in decompensated alcoholic liver disease: what is the impact on liver histology and gene expression patterns? Stem Cell Res Ther 2017;8(1):88.

[4] Pers YM, Rackwitz L, Ferreira R, Pullig O, Delfour C, Barry F, et al. Adipose Mesenchymal Stromal Cell-Based Therapy for Severe Osteoarthritis of the Knee: A Phase I Dose-Escalation Trial. Stem Cells Transl Med 2016;5(7):847-56.

[5] Morrison DA, Kop AM, Nilasaroya A, Sturm M, Shaw K, Honeybul S. Cranial reconstruction using allogeneic mesenchymal stromal cells: a phase 1 first-in-human trial. Tissue engineering. Part C. Methods 2017;12(2):341-8. 
[6] Stanovici J, Le Nail LR, Brennan MA, Vidal L, Trichet V, Rosset $\mathrm{P}$, et al. Bone regeneration strategies with bone marrow stromal cells in orthopaedic surgery. Curr Res Transl Med 2016;64(2):83-90.

[7] Sakkas A, Wilde F, Heufelder M, Winter K, Schramm A. Autogenous bone grafts in oral implantology-is it still a "gold standard"? A consecutive review of 279 patients with 456 clinical procedures. Int J Implant Dent 2017;3(1):23.

[8] Swan MC, Goodacre TE. Morbidity at the iliac crest donor site following bone grafting of the cleft alveolus. Br J Oral Maxillofac Surg Title 2006;44(2):129-33.

[9] Lee SH, Yoo CJ, Lee U, Park CW, Lee SG, Kim WK. Resorption of Autogenous Bone Graft in Cranioplasty: Resorption and Reintegration Failure. Korean J Neurotrauma 2014;10(1):10-4.

[10] Yin J, Jiang Y. Completely resorption of autologous skull flap after orthotopic transplantation: a case report. J Clin Exp Med 2014;7(4):1169-71.

[11] Crisan M, Yap S, Casteilla L, Chen CW, Corselli M, Park TS, et al. A perivascular origin for mesenchymal stem cells in multiple human organs. Cell stem cell 2008;3(3):301-13.

[12] Fekete N, Rojewski MT, Furst D, Kreja L, Ignatius A, Dausend $\mathrm{J}$, et al. GMP-compliant isolation and large-scale expansion of bone marrow-derived MSC. PloS one 2012;7(8):e43255.

[13] Rojewski MT, Fekete N, Baila S, Nguyen K, Furst D, Antwiler D, et al. GMP-compliant isolation and expansion of bone marrow-derived MSCs in the closed, automated device quantum cell expansion system. Cell Transplant 2013; 22(11):1981-2000.

[14] Wuchter P, Bieback K, Schrezenmeier H, Bornhauser M, Muller LP, Bonig $\mathrm{H}$, et al. Standardization of Good Manufacturing Practice-compliant production of bone marrowderived human mesenchymal stromal cells for immunotherapeutic applications. Cytotherapy 2015;17(2):128-39.

[15] Gomez-Barrena E, Rosset P, Gebhard F, Hernigou P, Baldini $\mathrm{N}$, Rouard $\mathrm{H}$, et al. Feasibility and safety of treating non-unions in tibia, femur and humerus with autologous, expanded, bone marrow-derived mesenchymal stromal cells associated with biphasic calcium phosphate biomaterials in a multicentric, non-comparative trial. Biomaterials 2018.

[16] Fernández O, Izquierdo G, Fernández V, Leyva L, Reyes V, Guerrero M, et al. Adipose-derived mesenchymal stem cells (AdMSC) for the treatment of secondary-progressive multiple sclerosis: A triple blinded, placebo controlled, randomized phase I/II safety and feasibility study. PloS one 2018;13 (5): $\mathrm{e} 0195891$.

[17] Detry O, Vandermeulen M, Delbouille M-H, Somja J, Bletard $\mathrm{N}$, Briquet A, et al. Infusion of mesenchymal stromal cells after deceased liver transplantation: A phase I-II, open-label, clinical study. J Hepatol 2017;67(1):47-55.

[18] Alvaro-Gracia JM, Jover JA, Garcia-Vicuna R, Carreno L, Alonso A, Marsal S, et al. Intravenous administration of expanded allogeneic adipose-derived mesenchymal stem cells in refractory rheumatoid arthritis (Cx611): results of a multicentre, dose escalation, randomised, single-blind, placebocontrolled phase Ib/IIa clinical trial. Ann Rheum Dis 2017; 76(1):196-202.

[19] Lamo-Espinosa JM, Mora G, Blanco JF, Granero-Moltó F, Nuñez-Córdoba JM, Sánchez-Echenique C, et al. Intraarticular injection of two different doses of autologous bone marrow mesenchymal stem cells versus hyaluronic acid in the treatment of knee osteoarthritis: multicenter randomized controlled clinical trial (phase I/II). J Transl Med 2016;14 (1):246.

[20] Vega A, Martín-Ferrero MA, Del Canto F, Alberca M, García V, Munar A, et al. Treatment of Knee Osteoarthritis With Allogeneic Bone Marrow Mesenchymal Stem Cells: A
Randomized Controlled Trial. Transplantation 2015;99 (8):1681-90.

[21] Introna M, Lucchini G, Dander E, Galimberti S, Rovelli A, Balduzzi A, et al. Treatment of graft versus host disease with mesenchymal stromal cells: a phase I study on 40 adult and pediatric patients. Biol Blood Marrow Transplant 2014;20 (3):375-81.

[22] European Comission. Regulation (EC) No 1394/2007 of the European Parliament and of the Council of 13 November 2007 on advanced therapy medicinal products and amending Directive 2001/ 83/EC and Regulation (EC) No $726 / 2004$. Official Journal of the European Union 2007;50(1):121-37.

[23] Brennan MA, Renaud A, Amiaud J, Rojewski MT, Schrezenmeier H, Heymann D, et al. Pre-clinical studies of bone regeneration with human bone marrow stromal cells and biphasic calcium phosphate. Stem Cell Res Ther 2014;5 (5): 114

[24] Veronesi E, Murgia A, Caselli A, Grisendi G, Piccinno MS, Rasini $\mathrm{V}$, et al. Transportation conditions for prompt use of ex vivo expanded and freshly harvested clinical-grade bone marrow mesenchymal stromal/stem cells for bone regeneration. Tissue engineering. Part C. Methods 2014;20(3):239-51.

[25] Dominici M, Le Blanc K, Mueller I, Slaper-Cortenbach I, Marini F, Krause D, et al. Minimal criteria for defining multipotent mesenchymal stromal cells. The International Society for Cellular Therapy position statement. Cytotherapy 2006;8(4):315-7.

[26] Horwitz EM, Le Blanc K, Dominici M, Mueller I, SlaperCortenbach I, Marini FC, et al. Clarification of the nomenclature for MSC: The International Society for Cellular Therapy position statement. Cytotherapy 2005;7(5):393-5.

[27] Pharm PV. Minimal criteria of expanded mesenchymal stem cells for clinical application: Hypothesis and experiments. Cytotherapy 2016;18(6):S129.

[28] Rojewski MT, Lotfi R, Schrezenmeier H. Flow Cytometry Control of MSC used as ATMP for Clinical Trials (Durchflusszytometrische Kontrolle von MSC-Produkten im Rahmen der Herstellung als ATMP für klinische Prüfungen). Transfusionsmedizin 2015;5:142-6.

[29] Minonzio G, Corazza M, Mariotta L, Gola M, Zanzi M, Gandolfi E, et al. Frozen adipose-derived mesenchymal stem cells maintain high capability to grow and differentiate. Cryobiology 2014;69(2):211-6.

[30] Marquez-Curtis LA, Janowska-Wieczorek A, McGann LE, Elliott JA. Mesenchymal stromal cells derived from various tissues: Biological, clinical and cryopreservation aspects. Cryobiology 2015;71(2):181-97.

[31] Del Pino A, Ligero G, Lopez MB, Navarro H, Carrillo JA, Pantoll SC, et al. Morphology, cell viability, karyotype, expression of surface markers and plasticity of three human primary cell line cultures before and after the cryostorage in LN2 and GN2. Cryobiology 2015;70(1):1-8.

[32] Gramlich OW, Burand AJ, Brown AJ, Deutsch RJ, Kuehn $\mathrm{MH}$, Ankrum JA. Cryopreserved mesenchymal stromal cells maintain potency in a retinal ischemia/reperfusion injury model: Toward an off-the-shelf Therapy. Scientific reports 2016;6:26463

[33] Hoogduijn MJ, de Witte SF, Luk F, van den Hout-van Vroonhoven MC, Ignatowicz L, Catar R, et al. Effects of freeze-thawing and intravenous infusion on mesenchymal stromal cell gene expression. Stem Cells Dev 2016;25 (8):586-97.

[34] Heng BC, Richards M, Cao T. Are stem cells inherently more prone to cryopreservation-induced apoptosis compared to ordinary somatic cells? Hum Reprod 2009;24 (2):492-3 
[35] Ragoonanan V, Hubel A, Aksan A. Response of the cell membrane-cytoskeleton complex to osmotic and freeze/thaw stresses. Cryobiology 2010;61(3):335-44.

[36] Galipeau J. The mesenchymal stromal cells dilemma-does a negative phase III trial of random donor mesenchymal stromal cells in steroid-resistant graft-versus-host disease represent a death knell or a bump in the road? Cytotherapy 2013;15(1):2-8.

[37] EuropeanComission. Directive 2004/23/EC of the European Parliament and of the Council of 31 March 2004 on setting standards of quality and safety for the donation, procurement, testing, processing, preservation, storage and distribution of human tissues and cells. Official Journal of the European Union 2004;47:48-58.

[38] EuropeanComission. Commission Directive 2006/17/EC of 8 February 2006 implementing Directive 2004/23/EC of the European Parliament and of the Council as regards certain technical requirements for the donation, procurement and testing of human tissues and cells. Official Journal of the European Union 2006;49:40-52.

[39] Fekete N, Gadelorge M, Furst D, Maurer C, Dausend J, Fleury-Cappellesso S, et al. Platelet lysate from whole bloodderived pooled platelet concentrates and apheresis-derived platelet concentrates for the isolation and expansion of human bone marrow mesenchymal stromal cells: production process, content and identification of active components. Cytotherapy 2012;14(5):540-54.

[40] Fekete N, Rojewski MT, Lotfi R, Schrezenmeier H. Essential components for ex vivo proliferation of mesenchymal stromal cells. Tissue engineering. Part C. Methods 2014;20(2):129-39.

[41] Schwarz K, Iolascon A, Verissimo F, Trede NS, Horsley W, Chen W, et al. Mutations affecting the secretory COPII coat component SEC23B cause congenital dyserythropoietic anemia type II. Nat Genet 2009;41(8):936-40.

[42] Europäisches Arzneibuch. 8. Ausgabe Berlin: Deutscher Apotheker Verlag 2014.

[43] Janetzko K, Rink G, Hecker A, Bieback K, Kluter H, Bugert P. A single-tube real-time PCR assay for Mycoplasma detection as a routine quality control of cell therapeutics. Transfusion medicine and hemotherapy: offizielles Organ der Deutschen Gesellschaft fur Transfusionsmedizin und Immunhamatologie 2014;41(1):83-9.

[44] Stuhrmann-Spangenberg M. Qualitätssicherung in der humangenetischen Diagnostik. Bundesgesundheitsbl 2015;58:121-6.

[45] Stuhrmann-Spangenberg M, Engels H, Fritz B, Gabriel H, Gläser D, Henn W, et al. Leitlinien und Stellungnahmen. Deutsche Gesellschaft für Humangenetik e.V. (GfH), Berufsverband Deutscher Humangenetiker e.V. (BVDH): S2Leitlinie Humangenetische Diagnostik. Med Genet 2011;23:281-323.

[46] Hastings R, Howell R, Dagna Bricarelli F, Kristoffersson U, Cavani S. General Guidelines and Quality Assurance for Cytogenetics. A common European framework for quality assessment for constitutional, acquired and molecular cytogenetic investigations. E.C.A. Permanent Working Group for Cytogenetics and Society. ECA Newsletter 2012;29:75.

[47] Hastings R, Howell R, Dagna Bricarelli F, Kristoffersson U, Cavani S. Specific Constitutional Cytogenetic Guidelines. A common European framework for quality assessment for constitutional, acquired and molecular cytogenetic investigations. E.C. A. Permanent Working Group for Cytogenetics and Society. ECA Newsletter 2012;30:11-9.

[48] Gjerde C, Mustafa K, Hellem S, Rojewski M, Gjengedal H, Yassin MA, et al. Cell therapy induced regeneration of severely atrophied mandibular bone in a clinical trial. Stem Cell Res Ther 2018;9(1):213.
[49] Gomez-Barrena E, Padilla-Eguiluz NG, Avendano-Sola C, Payares-Herrera C, Velasco-Iglesias A, Torres F, et al. A Multicentric, Open-Label, Randomized, Comparative Clinical Trial of Two Different Doses of Expanded hBM-MSCs Plus Biomaterial versus Iliac Crest Autograft, for Bone Healing in Nonunions after Long Bone Fractures: Study Protocol. Stem Cells Int 2018;2018:6025918.

[50] Kurt Yuksel M, Topcuoglu P, Kurdal M, Ilhan O. The clonogenic potential of hematopoietic stem cells and mesenchymal stromal cells in various hematologic diseases: a pilot study. Cytotherapy 2010;12(1):38-44.

[51] Bartmann C, Rohde E, Schallmoser K, Purstner P, Lanzer G, Linkesch W, et al. Two steps to functional mesenchymal stromal cells for clinical application. Transfusion 2007;47(8):1426-35.

[52] Schallmoser K, Bartmann C, Rohde E, Reinisch A, Kashofer $\mathrm{K}$, Stadelmeyer E, et al. Human platelet lysate can replace fetal bovine serum for clinical-scale expansion of functional mesenchymal stromal cells. Transfusion 2007;47(8):1436-46.

[53] Banfi A, Bianchi G, Notaro R, Luzzatto L, Cancedda R, Quarto R. Replicative aging and gene expression in longterm cultures of human bone marrow stromal cells. Tissue engineering 2002;8(6):901-10.

[54] Beane OS, Fonseca VC, Cooper LL, Koren G, Darling EM. Impact of aging on the regenerative properties of bone marrow-, muscle-, and adipose-derived mesenchymal stem/stromal cells. PloS one 2014;9(12):e115963.

[55] Li Y, Charif N, Mainard D, Bensoussan D, Stoltz JF, de Isla N. Donor's age dependent proliferation decrease of human bone marrow mesenchymal stem cells is linked to diminished clonogenicity. Bio-medical materials and engineering 2014;24(1 Suppl):47-52.

[56] Henrich D, Nau C, Kraft SB, Zollfrank M, Kontradowitz K, Oppermann E, et al. Effect of the harvest procedure and tissue site on the osteogenic function of and gene expression in human mesenchymal stem cells. Int J Mol Med 2016;37 (4):976-88.

[57] Ibatici A, Caviggioli F, Valeriano V, Quirici N, Sessarego N, Lisa A, et al. Comparison of cell number, viability, phenotypic profile, clonogenic, and proliferative potential of adiposederived stem cell populations between centrifuged and noncentrifuged fat. Aesthetic Plast Surg 2014;38(5):985-93.

[58] Sensebe L, Tarte K, Galipeau J, Krampera M, Martin I, Phinney DG, et al. Limited acquisition of chromosomal aberrations in human adult mesenchymal stromal cells. Cell stem cell 2012;10(1):9-10. author reply -1.

[59] Barkholt L, Flory E, Jekerle V, Lucas-Samuel S, Ahnert P, Bisset L, et al. Risk of tumorigenicity in mesenchymal stromal cell-based therapies-bridging scientific observations and regulatory viewpoints. Cytotherapy 2013;15(7):753-9.

[60] Tarte K, Gaillard J, Lataillade JJ, Fouillard L, Becker M, Mossafa $\mathrm{H}$, et al. Clinical-grade production of human mesenchymal stromal cells: occurrence of aneuploidy without transformation. Blood 2010;115(8):1549-53.

[61] Rosland GV, Svendsen A, Torsvik A, Sobala E, McCormack $\mathrm{E}$, Immervoll $\mathrm{H}$, et al. Long-term cultures of bone marrowderived human mesenchymal stem cells frequently undergo spontaneous malignant transformation. Cancer research 2009;69(13):5331-9.

\section{Supplementary materials}

Supplementary material associated with this article can be found in the online version at doi:10.1016/j. jcyt.2019.03.001. 